\title{
Ethics of care in supporting disabled forced migrants: interactions with professionals and ethical dilemmas in health and social care in the South-East of England
}

Article

Accepted Version

Ottosdottir, G. and Evans, R. (2014) Ethics of care in supporting disabled forced migrants: interactions with professionals and ethical dilemmas in health and social care in the South-East of England. British Journal of Social Work, 44 (Sup.1). pp. 53-69. ISSN 1468-263X doi:

https://doi.org/10.1093/bjsw/bcu048 Available at https://centaur.reading.ac.uk/37422/

It is advisable to refer to the publisher's version if you intend to cite from the work. See Guidance on citing.

To link to this article DOI: http://dx.doi.org/10.1093/bjsw/bcu048

Publisher: Oxford Journals

All outputs in CentAUR are protected by Intellectual Property Rights law, including copyright law. Copyright and IPR is retained by the creators or other copyright holders. Terms and conditions for use of this material are defined in the End User Agreement. 


\section{www.reading.ac.uk/centaur}

\section{CentAUR}

Central Archive at the University of Reading

Reading's research outputs online 


\section{'A world on the move': Migration, Mobilities and Social Work}

Title of paper: Ethics of care in supporting disabled forced migrants: interactions with professionals and ethical dilemmas in health and social care in the South-East of England Authors: Gudbjorg Ottosdottir, PhD Research Student and Ruth Evans, Associate Professor in Human Geography, Department of Geography \& Environmental Science, University of Reading

\section{Contact details:}

Gudbjorg Ottosdottir, PhD Research Student (corresponding author)

Department of Geography \& Environmental Science

University of Reading

Whiteknights PO Box 227

Reading RG6 6AB

UK

Email: g.ottosdottir@pgr.reading.ac.uk

Dr Ruth Evans, Associate Professor in Human Geography

Department of Geography \& Environmental Science

University of Reading

Whiteknights PO Box 227

Reading RG6 6AB

UK

Email: $\underline{\text { r.evans@ @reading.ac.uk }}$

CGudbjorg Ottosdottir and Ruth Evans 13/03/14.

Please cite this paper as: Ottosdottir, G. and Evans, R. (2014) 'Ethics of care in supporting disabled forced migrants: interactions with professionals and ethical dilemmas in health and social care in the South-East of England', British Journal of Social Work, 44, Supplement 1, i53-i69, doi: 10.1093/bjsw/bcu048 


\section{Abstract (200 words)}

This article explores the interactions between disabled forced migrants with care needs and professionals and the restrictive legal, policy and practice context that health and social care professionals have to confront, based on the findings of a qualitative study with 45 participants in the South-East of England. In-depth interviews were conducted with 15 forced migrants who had diverse impairments and chronic illnesses ( 8 women and 7 men), 13 family caregivers and 17 support workers and strategic professionals working in social care and the third sector in Slough, Reading and London. The legal status of forced migrants significantly affects their entitlements to health and social care provision, resulting in prolonged periods of destitution for many families. National asylum support policies, difficult working relationships with UK Border Agency, higher eligibility thresholds and reduced social care budgets of local authorities were identified as significant barriers in responding to the support needs of disabled forced migrants and family caregivers. In this context, social workers experienced considerable ethical dilemmas. The research raises profound questions about the potential and limitations of health and social care policies, provision, and practice as means of protection and support in fulfilling the human rights of forced migrants with care needs. 


\section{Ethics of care in supporting disabled forced migrants: interactions with professionals and ethical dilemmas in health and social care in the South-East of England}

\section{Introduction}

Legal status and limited entitlements to social care often result in multiple levels of social exclusion for forced migrants with impairments in the UK and other countries in the global North (Straimer, 2011; Ward et al., 2008). Forced migrants face multiple barriers to accessing support and health and social care professionals encounter significant challenges in meeting their needs (Hayes and Humpries, 2004; Harris and Roberts, 2004; Robinson, 2013). However, few studies to date have focused on disabled forced migrants' and caregivers' everyday experiences of seeking health and social care support and the ethical values and practices of statutory and third sector agencies in meeting the needs of this 'hard to reach' group.

In this article, we use the term 'disabled people' to refer to people with a range of impairments and chronic illnesses that, in interaction with attitudinal and environmental barriers, hinder their full and effective participation in society on an equal basis with others (UNCRPWD, 2014). We use the term 'forced migrants' to refer to persons who migrate because their lives or livelihood is threatened because of events such as conflict, repression, natural or man-made [sic] disasters (IOM, 2014) and who have the legal status of refugees or who otherwise require humanitarian protection, or who have the status of asylum seekers or those who hold limited, discretionary or indefinite leave to remain in the UK. Forced migrants may be more likely to have higher health and care needs than other migrant groups due to sustaining physical or sensory impairments and/or experiencing torture or trauma before they fled their country of origin or during their journeys to a safe country (Jakobsen and Thoresen, (O)Gudbjorg Ottosdottir and Ruth Evans 13/03/14. 
2011; Momartin et al., 2003; Roberts and Harris, 2002). They may also experience significant mental illness in host countries with increasingly restrictive and punitive immigration policies, such as the UK (Chantler, 2012; Ruiz-Casares et al., 2010; Steel et al., 2006). This is related, at least in part, to prolonged periods of insecure immigration status, fear of deportation and/or detention and/or a worsening of existing health conditions or impairments when experiencing poverty and social exclusion. Paradoxically, however, forced migrants may experience more difficulties than other migrant groups in accessing services due to their legal status.

Research has highlighted the multiple barriers forced migrants with health impairments face in accessing formal support. Barriers may be structural, social or cultural or may relate to the challenges facing refugee and minority ethnic community organisations, which often become the key source of support in the absence of, or restrictions in, statutory provision (Straimer, 2011; Ward et al., 2008). While access to healthcare is dependent on formal policies, informal networks and support are also significant; language barriers, gender norms and stigmatisation mean that people may rely on receiving information from informal sources, such as from relatives, friends and neighbours (Gideon, 2011; Sabates-Wheeler and MacAuslan, 2007). Further difficulties are caused by the way that asylum support is structured and provisioned. The raising of thresholds to qualify for care support in a rapidly changing political and funding climate constrains the abilities of statutory and third sector professionals (including those working in Local Authority social services, the National Health Service (NHS) services and refugee and minority ethnic community-based organisations) to respond to the care needs of forced migrants (Robinson, 2013; Ward et al., 2008). 
Some studies have analysed professionals' experiences of supporting forced migrants (Guhan and Liebling-Kalifani, 2011; Hayes and Humpries, 2004). Social workers and professionals in local authorities, statutory and third sectors of social care in the UK have to work with two conflicting policies, that of the national framework for safeguarding vulnerable adults and children and the asylum and immigration policy. Both policies have been shown to create significant tensions in social workers' roles (Hayes and Humpries, 2004) and to have impacts on their own health and wellbeing (Guhan and Liebling-Kalifani, 2011; Robinson, 2013). Social workers in Local Authorities may become simultaneously 'agents of control' and 'gatekeepers of services' (Sales and Hek, 2004) as well as struggling to protect and prevent harm to vulnerable adults and children. Responding to the needs of disabled forced migrants with insecure legal status creates significant ethical dilemmas for professionals, and raises questions of human rights, care and social justice, principles which are central to social work.

This article explores the experiences of disabled forced migrants with care needs, informal caregivers and professionals, based on the findings of qualitative research conducted in the South-East of England. After giving an overview of the policy context and the research, we explore the interactions between forced migrants with care needs and statutory professionals and discuss how professionals respond to migrants' experiences within the constraints of the legal, policy and practice frameworks that govern their work. To conclude, we reflect on the questions these findings raise for professional practice and ethics of care in supporting disabled and chronically ill forced migrants and caregivers.

\section{Context}

The introduction of the Immigration and Asylum Act in 1999 led to considerable changes in asylum policy in the UK. Support to 'destitute' asylum seekers became the responsibility of (O)Gudbjorg Ottosdottir and Ruth Evans 13/03/14.

Please cite this paper as: Ottosdottir, G. and Evans, R. (2014) 'Ethics of care in supporting disabled forced migrants: interactions with professionals and ethical dilemmas in health and social care in the South-East of England', British Journal of Social Work, 44, Supplement 1, i53-i69, doi: 10.1093/bjsw/bcu048 
the UK Border Agency (UKBA) under the National Asylum Support Service (NASS) and entitlements to 'destitute support', financial support and housing support were tightened (Bowes et al., 2008; Sales, 2007). Support to asylum seekers with care needs arising from impairments and illnesses, however, continued to be the responsibility of local authorities (Harris, 2003). As part of the Home Office's dispersal housing policy, destitute asylum seekers tend to be accommodated in locations and housing which is not their preferred choice. This often results in social isolation and hardship as people are placed far away from sources of informal support, such as friends, relatives and minority ethnic communities (Bowes et al., 2008; Ward et al., 2008). Asylum seekers who are eligible for UKBA destitute support receive financial support which is 35 per cent lower than Income Support Benefit payments. Single asylum seekers aged 18 years or older receive $£ 36.62$ per week, while a single British citizen aged 16 to 24 years old receives $£ 56.80$ and those over 25 years receive $£ 71.70$ per week (Gov.uk, 2014; Home Office, 2014).

Health and social care professionals may experience considerable barriers in responding to the care needs of disabled asylum seekers (Robinson, 2013; Sales and Hek, 2004). The twotiered system of support to asylum seekers who are both destitute and have care needs means that professionals may become embroiled in negotiations between UKBA and local authorities about issues of eligibility in accessing support and whose duty it may be to respond to care needs (ibid). Structural barriers include: the tendency to prioritise control over responding to need, complex procedures, tightened criteria for community care assessments and a lack of alternative resources to provide the required support. Tensions between gate-keeping and responding become particularly acute in social work with disabled asylum seekers and refugees with limited entitlements to support. Social workers find that they are often unable to provide the support required (Newbigging and Thomas, 2011). When (O)Gudbjorg Ottosdottir and Ruth Evans 13/03/14. 
working with asylum seekers, principles in social work ethics, such as human rights and social justice, risk becoming significantly undermined.

\section{Theoretical approach}

In this article we draw on Tronto's (1993) ethics of care to conceptualise the social relations, practices and ethical values associated with providing care and support for disabled and chronically ill forced migrants. Care is understood as both a practice and a disposition (Tronto, 1993) involving a complex interaction between socio-cultural and ethical values of care, the identities of those 'giving' and 'receiving' care, social policy and practice and wider political and economic structures and processes (Evans and Thomas, 2009).

Tronto (1993, p.105) identifies four phases of the caring process: 'caring about'; 'taking care of'; 'care-giving'; and 'care-receiving' and four linked core ethical values: attentiveness being attentive to the needs of others; responsibility, which is 'embedded in implicit cultural practices'; competence to provide good care, which includes the availability of adequate resources; and responsiveness of the care-receiver to the care (Tronto, 1993, p. 131-136). 'Good care' is based on the integration of these four phases of the caring process into an appropriate whole. Tronto (1993, p. 109) acknowledges that the ideal of an integrated process of care is rarely achieved, due to the likelihood of conflict, often between caregivers' needs to care for themselves and the care they give to others, and the limited availability of adequate material or other resources. Drawing on psychotherapeutic approaches, Bondi (2008, p. 260) suggests that the notion of 'empathic understanding' enables caregivers to identify with carerecipients, in addition to enabling 'care-recipients to imagine what it might be like for caregivers to do what they do'. Bondi explains that this fosters good communication which helps 
to ensure that adequate feedback about whether needs for care have been met, corresponding to Tronto's ethical value of 'responsiveness' (Evans and Thomas, 2009).

In the literature on transnational and global care (Raghuram, 2012), the overwhelming emphasis on migrants as care-workers/'care-givers' ignores the fact that migrants, like other social groups, are likely to experience disability and chronic illness and have their own care needs. Raghuram (2012, p. 156) argues that deeper analysis of the locationally specific dynamics of care in diverse geographical contexts is needed, since, 'the provision of care is differentially embedded in cultural, political and economic formations such as the family, the market, the state and the community sector in different countries'. In this paper, we analyse the specific caring relations and interactions that disabled forced migrants with care needs and family caregivers develop with health and social care professionals in the South-East of England. As we show, their experiences need to be understood within the broader context of national asylum and immigration policies, differential entitlements to health and social care, funding constraints and other pressures that determine the broader 'landscape of care' (Milligan and Wiles, 2010).

\section{Research methods and ethical considerations}

This paper draws on analysis of qualitative research conducted by the first author that explored the experiences and perspectives of disabled refugee and asylum seekers, family members and other caregivers and professionals in the South-East of England. A purposive sample of 45 participants was identified through snowballing techniques and contacts with gatekeepers. Three differing locations (Slough, Reading and London) were selected in order to explore place-specific differences in social care provision and resources. 
In-depth interviews were conducted with 15 forced migrants ( 8 women and 7 men, aged 25 to 80 years) from 12 different countries of origin, including Afghanistan, Iraq, Pakistan, Somalia, Uganda, Zimbabwe, Sudan and Sri Lanka among others. Participants had a range of impairments and chronic illnesses, including mental health problems, physical impairments, learning disabilities, heart and coronary illness, arthritis, HIV and cancer; we recognise that not all of these participants necessarily identified as 'persons with disabilities' (UNCRPWD, 2014). Participants were asked to identify the person who provided them with significant care. In-depth interviews were conducted with ten family members (aged 13 to 78) and three nonkin significant others providing regular care support (aged 25 to 50). Two family caregivers were sons, three were daughters, one was a partner and two were parents. In total, of those with care needs and those giving care, 19 had been granted Indefinite Leave to Remain in the UK, six were seeking asylum, two had obtained British citizenship and one was undocumented at the time of research. Semi-structured interviews were conducted with 17 professionals working in statutory and third sector social care services that provided direct support to disabled people, carers and refugees and asylum seekers, including Local Authority social care departments, minority ethnic and refugee community organisations and carers' organisations.

Since forced migrants are recognised as a vulnerable social group who may experience multiple barriers (Birman, 2005), attention was paid to ensure that family members' participation was facilitated as much as possible. Ethical clearance was granted by the University of Reading Research Ethics Committee in September 2011. Time was taken to develop relationships of trust and to negotiate informed consent, confidentiality and anonymity and inform participants about the possible risks (possibility of evoking difficult emotions or memories) and benefits of taking part (their experiences would be heard). (O)Gudbjorg Ottosdottir and Ruth Evans 13/03/14. 
Participants received a small financial gift for their participation at the end of interviews andwritten consent was sought from all participants. Participants were offered the use of an interpreter and professional interpreters and staff and volunteers from refugee organisations who had been trained as interpreters were used in five interviews. Interview venues were chosen by participants and a flexible approach was adopted in order to allow for different kinds of impairments or time for translations. Care was taken not to probe about distressing experiences in order to minimise potential harm. Although my (first author's) position as a white European woman from a middle class background differed from that of the participants and sometimes, of professionals, my professional experience as a social worker with forced migrants meant that I was accustomed to approaching difficult issues with sensitivity and respect. This helped in minimising distress during interviews, signposting participants on to further sources of support and in gaining trust, credibility and legitimacy among professionals and participants. I (first author) took care to clarify with participants my role as a researcher and explained when appropriate what I could do on their behalf, as well as the limits of this role. .

All interviews were audio-recorded, transcribed, coded and analysed thematically. Summaries of each interview were written to assist in reading across the data. Pseudonyms have been used throughout this paper. The small sample does not aim to be representative of the population of forced migrants with impairments or caregivers in the UK or of the experiences of social care professionals, but rather provides in-depth insights into a diverse range of experiences, perspectives and circumstances.

\section{Interactions between forced migrants and professionals in seeking support}


The research found that asylum support policies, NHS and Local Authority service provision that should reach out to 'vulnerable' adults and children, in line with the UK government policies on safeguarding vulnerable adults (Department of Health, 2011), and vulnerable children (HM Government, 2013), did not meet the needs of some participants. According to professionals, local authorities prioritised limited resources, which had direct implications for those who had limited legal rights to support, such as asylum seekers and 'failed' asylum seekers. Migrants' difficulties in access to healthcare need to be understood within the context of wider public concerns in the UK about 'health tourism' and assumptions that migrants from outside the European Economic Area (EEA) are moving to the UK to access free health care (an idea widely portrayed in the UK media) and placing a financial burden on the NHS. The Department of Health's (DOH) (2013) recent public consultation emphasises the need to regulate migrants' access to NHS healthcare by introducing fees for migrants from states outside of the EEA. Research suggests, however, that migrants from within (rather than outside) the EEA enter the UK for medical purposes and health tourism produces financial gains rather than a drain on the NHS (Hanefield et al., 2013). The DOH's emphasis on the role of frontline health services in identifying chargeable migrants means that healthcare professionals, such as General Practitioners (GPs), are under pressure to not only deliver clinical practice, but also to control entitlements to health services.

Most participants were entitled to free access to NHS primary care. In practice, however, they did not necessarily receive the healthcare they needed, reflecting Harris and Roberts' (2004) findings. While limited entitlements, language and information barriers were partly to blame, participants' experiences also suggest that GPs lacked knowledge of asylum seekers' rights. Professionals commented that funding pressures influenced GPs' responses, contributing to a situation where the NHS and Local Authorities were both reluctant to pick up the financial (O)Gudbjorg Ottosdottir and Ruth Evans 13/03/14. 
costs of care for disabled 'failed' asylum seekers (whose asylum claim has been rejected), which affected the outcome of care assessments. According to national policy, 'failed' asylum seekers do not have 'Recourse to Public Funds' (Home Office, 2013). By law, GPs, however, have the discretion to treat 'failed' asylum seekers, as stipulated in medical ethics.

In the experiences of a few participants, such an ethic of care did not always translate into practice. Nasir (aged 45 from Iran) had a physical impairment that he sustained in the process of travelling to the UK. Despite seeking healthcare from his GP, his impairment remained untreated due to an inability to pay medical fees following the rejection of his asylum claim:

"I went then to the GP and they said they could not see me either because I had to pay for their service. I had to pay for health support after my asylum case was rejected. But I had gone to the hospital right away after my asylum was refused, but they still refused to see me”.

Access to health care is thus also shaped by professionals' informal practices and responses. Policy and funding priorities alongside the difficulty of keeping up with frequents changes in rights and entitlements of asylum seekers are likely to play a role in health professionals' responses. Nasir's health condition in fact deteriorated further as a result of not gaining access to medical treatment. Such examples suggest that Home Office policies and funding pressures are undermining core ethical values, such as health professionals' 'responsibility' and 'competence' to provide care, leading to a lack of 'attentiveness' and 'responsiveness' to forced migrants' needs (Tronto, 1993). 
NHS and social care responses also appeared to be shaped by an implicit hierarchy of illness and impairment, with some illnesses and infections which pose a public health risk, such as $\mathrm{HIV}$, regarded as requiring more urgent action than others. Of 15 participants with impairments and chronic illness in the sample, five were living with HIV. These participants found that their health and social care needs were met immediately. Such experiences were in stark contrast to those of participants with impairments related to infirmity in old age or mental health problems, who only received care when their health problems reached crisis point. Health and social care responses may thus be governed not just by intentions to provide care and to protect vulnerable groups, but also to target specific groups who are deemed to present a 'risk' to society because of the nature of their illness (Pussetti and Barros, 2012). Place-based differences also affected participants' experiences; local authorities differed in terms of their priorities and availability of resources. For instance, in Slough, partnerships between refugee and carers' organisations and Local Authorities, was much less common than in other research locations.

Participants had mixed experiences of communicating with local authority social care professionals. Their experiences sometimes confirmed their perceptions of a hierarchy of needs based on their legal status and racial discrimination, as Susan, a young carer (aged 25) with Limited Leave to Remain (LLR) from Zimbabwe, found when seeking support from social services:

\section{"If you call the council's offices they are very quick to tell you that you are not entitled with a Limited Leave to Remain and 'Can I take your name please?' and 'oh, I am afraid you are not entitled. [....] I am a tax payer and therefore I should be entitled to',}


but they say, 'no'. They don't know me, because either they just hear the name and then automatically they assume you are an immigrant and not entitled".

Some participants described being treated with a lack of respect and dignity when dealing with statutory social services and finding professionals unresponsive and lacking empathy when they sought support, which could potentially result in feelings of disempowerment and disengagement with sources of support. Contextual social work practice emphasises the need to view the person holistically within their social environment, to seek to empower clients and have their best interests at heart (BASW, 2012) and the particular challenges of working in the field of migration are recognised by The College Of Social Work (TCSW) (2012). Our research suggests, however, that the policy and funding context in which social care professionals work, including tighter thresholds for care assessments, trickles down into relationships with vulnerable adults and children and shapes responses to disabled forced migrants with care needs. Social workers become embroiled in internal processes of negotiating funding and responsibilities with UKBA. Such pressures may undermine professionals' ability to provide 'good care' and principles of social justice and care, that are central to social work ethics, risk becoming lost when gate-keeping to restrict access to services becomes of more importance.

Time, complex layers of bureaucracy and frequent changes in social workers also affected participants' interactions and hindered the development of an ethics of care. Minimal levels of engagement with families with complex needs resulted in feelings of mistrust and a perception that social workers did not care about their clients' needs. Lyad was a married man in his 40s from Sudan who cared for his cousin with mental illness. His cousin had an allocated social worker who was expected to pay him regular visits. Lyad felt the social 
worker did not spend enough time engaging with his cousin and expressed his frustrations with the social worker's apparent lack of care about their client:

"He is slow in reacting and he does not give you answers straight away and is not quick in deciding. The social worker should understand that. They should not just, "oh are you alright," and just quickly leave. He does not understand that very quickly visit ok! So if he had somebody that knew him, understood him and came to him and talked to him regularly it would make life easier for him. He should be allocted more time I think they need to give him more time and listen to him"

This suggests that Tronto's (1993) core ethical values of 'attentiveness' and 'responsiveness' that are integral to 'good care' may be missing, due to professionals' limited 'responsibility' and 'competence', in terms of available resources, such as time and human resources, to meet forced migrants' care needs.

Relationships with individual social workers and their ethical values, were found to make a key difference in terms of the level and nature of support participants were able to secure, which was especially evident in efforts to seek local authority care support and housing. Attributes such as caring, empathy, respect and understanding were highly regarded by participants. Social workers who made the effort to advocate on their behalf and push against constraints, or those who sought a range of alternative solutions in order to ensure that participants' wellbeing and mobility were sustained, were particularly valued. 
Susan, a young carer with Limited Leave to Remain, commented on the strong ethical values of a social worker, which showed a high level of responsiveness, 'empathic understanding' (Bondi, 2008) and commitment to improve the family's situation. Her mother was ill with cancer without rights to welfare support at the time and Susan struggled to care for her mother and two siblings, whilst doing two paid jobs. In contrast to previously stigmatising encounters with professionals linked to their marginal status as asylum seekers and immigrants with limited legal entitlements, Susan explained that the social worker treated them with respect and advocated on their behalf. Her mother was finally granted Leave to Remain and the family was able to access welfare benefits:

\begin{abstract}
"The way she [social worker] was compared to the way the people at [other organisation] acted. Maybe she was like that because she had Christian values or she is someone who believes in karma. She just did her job right. She didn't look though as if we were refugees or immigrants, she made it sure we did not feel that way. [...] She really pushed, she actually, literally pushed. You know most people, the local council people were very laid back and relaxed [...] very reluctant to do much, do get involved and help. She actually really, really, really, really did push...".
\end{abstract}

As highlighted here, social workers' advocacy roles may be of crucial importance in working with forced migrants with impairments and family carers, as TCSW (2012) recognises.

Relationships characterised by respect, trust and empathy that developed with professionals, including social workers and those working in the third sector, were important sources of support for disabled forced migrants and informal caregivers. In the face of barriers to service provision and in the absence of trusting relationships with professionals, however, participants (O)Gudbjorg Ottosdottir and Ruth Evans 13/03/14.

Please cite this paper as: Ottosdottir, G. and Evans, R. (2014) 'Ethics of care in supporting disabled forced migrants: interactions with professionals and ethical dilemmas in health and social care in the South-East of England', British Journal of Social Work, 44, Supplement 1, i53-i69, doi: 10.1093/bjsw/bcu048 
resorted to alternative care resources and informal support from relatives, friends and others in their neighbourhood.

\section{Ethical and practical dilemmas for social care professionals}

Professionals identified national asylum support policies, difficult working relationships with UKBA, a tightening of the thresholds for support and local authorities' reduced social care budgets as significant barriers in responding to the care needs of disabled forced migrants. Social work with vulnerable forced migrants became a complex process of balancing personal and professional ethical values with the support that could legally be provided. This suggests that ethical dilemmas continue to be a significant source of tension in social workers' work with forced migrants, as previous research found (Guhan and Liebling-Kalifani, 2011; Robinson, 2013). Social workers negotiated these constraints by drawing on a range of resources, including: their own agency, skills and efforts in negotiating bureaucratic systems and procedures; ethics of care, empathic understanding and responsiveness; and drawing on professional networks and seeking 'joined-up' service provision where possible.

Although the principles of safeguarding adults and children were supposed to guide multiagency collaborations (including between Local Authority social services and the NHS), funding pressures meant that in practice any collaboration was challenging and often took the form of 'fighting' about approaches, roles and responsibilities. Tightened eligibility criteria for an assessment of 'care needs' made it difficult for social workers to negotiate support for disabled forced migrants who had limited legal entitlements to support. The separation of adults' and children's services also hindered collaboration, as previous research has highlighted (Grady, 2004). UKBA policies which place issues of immigration control centre- 
stage conflict with health and social care policies and provision, resulting in an individual's legal status becoming the reference point rather than the best interests of the adult and child.

One social worker, commented on the rapidly changing legal and policy context, referring to the ways that eligibility criteria for care support had been tightened following the House of Lords' 2008 redefinition of the responsibilities of Local Authorities to provide support to asylum seekers with care needs: "If we're not breaching their human rights then we can't support them. There are people that we've withdrawn services from. In 2008 we used to provide services, then the law changed in 2008 and we had to say, 'well, you're not our responsibility'". Nevertheless, Local Authorities have a legal obligation to provide services to forced migrants who are destitute and have care needs arising from disability or ill health. The care support they are entitled to depends on the care assessment. Local Authorities can, however, refuse to undertake an assessment if the person is deemed not to fulfil the eligibility criteria of having 'care needs'. The assessment process is thus a process of negotiating internally between teams within Local Authorities and externally with UKBA about the underlying causes of care needs. Is the care need the result of destitution or the result of a pre-existing impairment or illness and whose responsibility is it to fund the support? Social workers become embroiled in such negotiations and their responses to families are dependent on the outcomes of these processes.

Social workers required skill and persistence in order to negotiate support for families and advocate on their behalf. In their experience, it was usually only when participants' impairments and need for care had progressed to a crisis situation that forced migrant families were able to receive local authority support. These negotiations were usually made in conjunction with a fresh claim for asylum being filed by their solicitors on human rights (C)Gudbjorg Ottosdottir and Ruth Evans 13/03/14. 
grounds. Outcomes of care assessments were thus related to funding and changes in forced migrants' legal status, as much as being led by human rights principles or the principles of safeguarding vulnerable adults and children.

Local authority professionals claimed they were not involved in the legal matters of forced migrant families, other than encouraging them to seek legal advice and referring them to appropriate third sector services when they were refused access to statutory social care. They did however seek to advocate for forced migrants and put pressure on UKBA to process asylum claims when there were concerns about human rights violations, particularly in complex cases, alongside the work of refugee and other third sector organisations. Social workers sought to negotiate the constraints of their role by drawing on professional networks with third sector organisations to try to influence the legal outcomes of families' asylum claims.

The Dispersal Policy provides an additional challenges. Many families are reluctant to be dispersed because they fear losing access to formal and informal networks of support in the locality where they originally settled in the UK. Social workers were not usually permitted to seek local authority support for clients who refused to be dispersed, as one social worker commented:

"We're saying it's not our responsibility, it's NAM's [New Asylum Model for asylum claims introduced in 2007 to speed up the decision-making process. Asylum claims since 2007 are called NAM cases]. We're saying, 'why should we foot the bill? ' So, if the person refuses, then we don't touch them, because refusing to be dispersed is their choice! We look at it as a choice and we give them that choice!" CGudbjorg Ottosdottir and Ruth Evans 13/03/14. 
However even if families refuse UKBA 'destitute support', the local authority could still be forced to provide support even if the family did not fit the criteria for care assessments. This is because families end up presenting with high and complex support needs as a result of long-term destitution; their situation reaches crisis point and they are then subject to care assessments and negotiations between the Local Authority and NASS. Professionals also believed that local authority-supported asylum seekers waited for long periods for decisions on their claims and suggested that cases being funded by the local authority were perhaps regarded as less of a priority by UKBA. Professionals advised families about the potential impact of remaining in the care of the local authority on their asylum claims, as a means of trying to deter families from refusing to be dispersed and the local authority having to meet the support costs.

Negotiating support between local authorities and UKBA is thus a complicated and highly political process, resulting in strained relations between all those involved. Social workers described feeling misunderstood by clients and by third sector professionals who made demands that social workers found hard to meet. When confronted with clients' perceptions that social workers were 'uncaring' and claims by the third sector refugee and ethnic communities that social workers 'treat clients like paper', one social worker responded that clients were not always truthful and that a minority tried to manipulate the system in order to obtain refugee status in the UK. Such views unfortunately reproduce negative public perceptions and media representations of asylum seekers as 'bogus', 'untrustworthy' and 'undeserving'.

Some social workers acknowledged how difficult it was to balance their personal and ethical values with the legal, policy and funding situation they faced. Maddie commented on a (O)Gudbjorg Ottosdottir and Ruth Evans 13/03/14. 
tendency for social workers to get 'bogged down' in bureaucratic procedures in attempting to secure service provision for vulnerable adults. This meant that they could lose sight of fundamental human rights principles and professional ethics of care that adopt a holistic approach to the person's needs:

\begin{abstract}
"Sometimes we're just, we're so bogged down in the processes, in the procedural, that sometimes we forget that there is a person there that needs reassurance, that is going through a crisis. And then we will be bickering amongst ourselves about what to do about it and it's frustrating sometimes because you've been there and you've seen the client, you know the pressures and you know the risks, and the officers and the managers are saying, 'oh, mental health, they haven't got a psychiatrist ready', and you have to wait for that...."
\end{abstract}

Indeed, the assessment process itself may delay people's access to support, especially if people have complex needs that 'need to be untangled' due to the narrow definition of 'care need', funding pressures and different sets of legislations governing professional roles and approaches in health and social care. Multi-agency collaboration is a significant challenge in this context.

\title{
Conclusion
}

This research suggests that the legal and policy context of national asylum and immigration policies, differential entitlements to health and social care and funding pressures within statutory services (including the NHS, housing, social services) dominate the 'landscape of care' (Milligan and Wiles, 2010) in which disabled and chronically ill forced migrants and family members find themselves in the UK. This has detrimental effects on the relations of (O)Gudbjorg Ottosdottir and Ruth Evans 13/03/14. 
care and support that can develop between disabled forced migrants, informal caregivers and professionals.

Although most participants were entitled to free NHS primary care, in practice they did not necessarily receive the healthcare they needed, revealing discrepancies between policy and practice (Harris and Roberts, 2004). Healthcare responses tended to be governed not only by intentions to protect and meet the healthcare needs of forced migrants, but also by concerns about the 'risk' that specific groups, such as people living with HIV, may pose to public health (Pussetti and Barros, 2012). In some instances, a lack of knowledge among General Practitioners about asylum seekers' and 'failed' asylum seekers' entitlements resulted in a failure to meet their healthcare needs and a deterioration in their condition. This needs to be understood within the context of rapidly changing UK immigration policies influenced by concerns about 'health tourism' and pressure to control migrants' entitlements to NHS services (DOH, 2013).

Similarly, funding restrictions and divided responsibilities between UKBA and Local Authorities caused tensions in interactions between professionals and disabled forced migrants and caregivers. Some participants described being treated with a lack of respect and dignity and finding professionals unresponsive and lacking empathy when they sought support. Tightened eligibility criteria for an assessment of 'care needs' made it difficult for social workers to negotiate support for forced migrants with impairments who had limited legal entitlements to support. Social workers were caught between increasingly restrictive and punitive Home Office policies and diminishing local authority funding and service provision for forced migrants with complex support needs. Outcomes of care assessments were related to funding and changes in forced migrants' legal status, as much as being influenced by (O)Gudbjorg Ottosdottir and Ruth Evans 13/03/14. 
human rights principles or the principles of safeguarding vulnerable adults and children. Some social workers acknowledged how difficult it was to balance their personal and professional ethical values with these pressures.

This paper has revealed the usefulness of an ethics of care perspective in conceptualising the interactions between disabled forced migrants, informal care-givers and professionals, and in drawing attention to the ethical dilemmas, tensions and conflicts that may arise between forced migrants' support needs, available resources and the wider political and socioeconomic context in which professionals work. These pressures shape social work practice and may override important professional practices and ethical values. Disabled forced migrants and informal caregivers associated 'good care' with individual personalities, a willingness to act, persevere and advocate on their behalf, empathic understanding (Bondi, 2008), attitudes and ethics of care and respect. Positive interactions enabled good communication to take place and resulted in a high level of responsiveness and relations of trust between forced migrants and some health and social care professionals.

The research raises profound questions about the potential and limitations of health and social care policies, provision, and practice as a means of protection and support in fulfilling the human rights of forced migrants with care needs. Ethics of care and social work practice are central to the development of positive interactions and encounters between marginalised groups and professionals. Alongside recognition of the multiple barriers to accessing services that forced migrants, especially those who are disabled and/or family carers, face (TCSW, 2012), the research suggests that training and ongoing education in how to apply ethical values is needed in social work education in future, within such restrictive and rapidly changing policy contexts. Although the ideal of an integrated process of 'good care' may be (O)Gudbjorg Ottosdottir and Ruth Evans 13/03/14. 
rarely achieved, due to the ways that care providers' competence to care is undermined by limited availability of resources (Tronto, 1993), advocacy support and ethical values of 'attentiveness', 'responsibility' and 'responsiveness' may still make an important difference to the lives of disabled forced migrants' and those who care for them.

\section{References}

British Association of Social Workers (BASW). (2012). 'The Code of Ethics for Social Work: Statement of Principles' available online at http://cdn.basw.co.uk/upload/basw_112315-7.pdf (accessed 27/09/12).

Birman, D. (2005). 'Ethical Issues in Research with Immigrants and Refugees', in Trimble, J. E. and Fisher, C. B. (eds.) The Handbook of Ethical Research with Ethnocultural Populations and Communities, Thousand Oaks and London, Sage Publishing.

Bondi, L. (2008). 'On the relational dynamics of caring: A psychotherapeutic approach to emotional and power dimensions of women's care work', Gender, Place and Culture, 15(3),pp.227-243.

Bowes, A., Ferguson, I., and Sim, D. (2008). 'Asylum policy and asylum experiences: Interactions in a Scottish context', Ethnic and Racial Studies, 32(1),pp.23-43.

Chantler, K. (2012). 'Gender, asylum seekers and mental distress: Challenges for mental health social work', British Journal Of Social Work, 42(2),pp.318-334.

Department of Health (DOH). (2011). 'Adult safeguarding: statement of government policy' available online at https://www.gov.uk/government/publications/adultsafeguarding-statement-of-government-policy (accessed 27/9/13).

DOH ( 2013). 'Sustaining services, sustaining fairness'

available online at http://www.gov.uk/government/uploads/attachment_data/file/210438/ (C) Gudbjorg Ottosdottir and Ruth Evans 13/03/14.

Please cite this paper as: Ottosdottir, G. and Evans, R. (2014) 'Ethics of care in supporting disabled forced migrants: interactions with professionals and ethical dilemmas in health and social care in the South-East of England', British Journal of Social Work, 44, Supplement 1, i53-i69, doi: 10.1093/bjsw/bcu048 
(accessed 30/12/13).

Evans, R. and Thomas, F. (2009). 'Emotional interactions and an ethic of care: caring relations in families affected by HIV and AIDS', Emotions, Space and Society, 2, pp.111-119.

Gideon, J. (2011). 'Exploring migrants' health seeking strategies: the case of Latin American migrants in London', International Journal of Migration, Health and Social Care, 7(4),pp.197-208.

Gov.uk (2014). 'Income support' available online at https://www.gov.uk/incomesupport/what-youll-get (accessed 29/01/14).

Grady, P. (2004). 'Social Work Responses to Accompanied Asylum-seeking Children’, In Hayes, D. and Humpries, B. (eds.) Social Work, Immigration and Asylum:

Debates,Dilemmas and Ethical Issues for Social Work and Social Care Practice, London: Jessica Kingsley Publishers.

Guhan, R. and Liebling-Kalifani, H. (2011). 'The experience of staff working with refugees and asylum seekers in the United Kingdom: A grounded theory exploration', Journal of Immigrant and Refugee Studies, 9,pp.205-228.

Hanefield, J., Lunt, N. and Smith, R. (2013). 'Health tourism and the NHS: Facts or fiction?', Lancet, 382(9890),pp.E2-E2.

Harris, J. (2003). 'All Doors are Closed to Us: A social model analysis of the experiences of disabled refugees and asylum seekers in Britain', Disability \& Society, 18(4), pp. 395-410.

Harris, J. and Roberts, K. (2004). 'Not Our Problem: The Provision of Services to

Disabled Refugees and Asylum-seekers', in Hayes, D. and Humpries, B. (eds.), Social Work,Immigration and Asylum: Dilemmas and Ethical Issues for Social Work and Social Care Practice, London, Jessica Kingsley Publishers.

Hayes, D. and Humpries, B. (eds.) (2004). Social Work, Immigration and Asylum: (O)Gudbjorg Ottosdottir and Ruth Evans 13/03/14. migrants: interactions with professionals and ethical dilemmas in health and social care in the South-East of England', British Journal of Social Work, 44, Supplement 1, i53-i69, doi: 10.1093/bjsw/bcu048 
Debates, Dilemmas and Ethical Issues for Social Work and Social Care Practice, London, Jessica Kingsley Publishers.

HM Government. (2013). 'Working together to safeguard children' available online at http://www.workingtogetheronline.co.uk/documents/Working\%20TogetherFINAL.pdf. (accessed 27/09/13).

Home Office. (2013). 'Public funds' available online at http://www.ukba.homeoffice.gov.uk/visas-immigration/while-inuk/rightsandresponsibilities/publicfunds/ (accessed 27/09/13).

Home Office. (2014). 'Current support amounts' available online at http://www.ukba.homeoffice.gov.uk/asylum/support/cashsupport/currentsupportamounts/ (accessed 28/01/2014).

International Organization for Migration (IOM). (2014). 'Key migration terms' available online at http://www.iom.int/cms/en/sites/iom/home/about-migration/key-migrationterms-htm1\#Forced-migration (accessed 28/01/14).

Milligan, C. and Wiles, J. (2010). 'Landscapes of care', Progress in Human Geography, 34(6),pp.736-754.

Momartin, S., Silove, V., Manicavasagar, Z., and Steel, Z. (2003). 'Dimensions of trauma associated with posttraumatic stress disorder (PTSD) caseness, severity and functional impairment: A study of Bosnian refugees resettled in Australia', Social Science \& Medicine, 57(5),pp.775-781.

Newbigging, K. and Thomas, N. (2011). 'Good practice in social care for refugee and asylum seeking children', Child Abuse Review, 20(5), pp. 374-390.

Pussetti, C. and Barros, V. (2012). 'The care of the immigrant self: technologies of citizenship and the healthcare sector', International Journal of Migration, Health and Social Care, $8(1), \mathrm{pp} .42-50$.

(O)Gudbjorg Ottosdottir and Ruth Evans 13/03/14.

Please cite this paper as: Ottosdottir, G. and Evans, R. (2014) 'Ethics of care in supporting disabled forced migrants: interactions with professionals and ethical dilemmas in health and social care in the South-East of England', British Journal of Social Work, 44, Supplement 1, i53-i69, doi: 10.1093/bjsw/bcu048 
Raghuram, P. (2012). 'Global care, local configurations - challenges to conceptualizations of care', Global networks, 12(2),pp.155-174.

Roberts, K. and Harris, J. (2002). Disabled people in Refugee and Asylum Seeking Communities, Bristol: Joseph Rowntree Foundation/Policy Press.

Robinson, (2013). Supervision found wanting: Experiences of health and social workers in non-government organisations working with refugees and asylum Seekers,

Practice: Social Work in Action, 25(2), pp. 87-103.

Ruiz-Casares, M., Rousseau, C., Derluyn, I., Watters, C. and Crépeau, F. (2010) 'Right and access to healthcare for undocumented children: Addressing the gap between international conventions and disparate implementations in North America and Europe', Social Science and Medicine, 70(2),pp.329-336.

Sabates-Wheeler, R. and MacAuslan, I. (2007). 'Migration and social protection: Exposing problems of access', Development, 50,pp.26-32.

Sales, R. and Hek, R. (2004). 'Dilemmas of care and control: The Work of an Asylum Team in a London borough', in Hayes, D. and Humpries, B. (eds.), Social Work, Immigration and Asylum: Dilemmas and Ethical Issues for Social Work and Social Care Practice, London, Jessica Kingsley Publishers.

Sales, R. (2007). Understanding Immigration and Refugee Policy: Contradictions and Continuities, Bristol, Policy Press.

Steel, Z., Momartin, S., Silove, D., Coello, M., Aroche, J., and Tay, K. W. (2006). 'Two year psychosocial and mental health outcomes for refugees subjected to restrictive or supportive immigration policies', Social Science \& Medicine, 72(7),pp.1149-1156.

Straimer, C. (2011). 'Between protection and assistance: Is there refuge for asylum seekers with disabilitities in Europe?', Disability \& Society, 26(5),pp.537-551. 
The College of Social Work (TCSW) (2012). 'Curriculum guide: Migration and Refugees' available online at http: www. Tcsw.org.uk/uploadedFiles/TheCollage/Media centre /CG Migration refugees.pdf (accessed 30/12/13).

Tronto, J. (1993). Moral Boundaries: A Political Argument for an Ethic of Care, New York and London, Routledge.

UNCRPWD (2014) United Nations Convention on the Rights of Persons with Disabilities, available online at http://www.un.org/disabilities/convention/conventionfull.shtml (accessed 12/03/14).

Ward, K., Amas, N., and Lagnado, J. (2008). Supporting disabled refugees and asylum seekers:opportunities for new approaches, London, London Metropolitan Support Trust. 